\title{
Comorbidities and clinical features related to severe outcomes among COVID-19 cases in Selangor, Malaysia
}

Wan Shakira Rodzlan Hasani, 'a Shubash Shander Ganapathy, ${ }^{a}$ Chong Zhuo Lin, ${ }^{a}$ Halizah Mat Rifin,

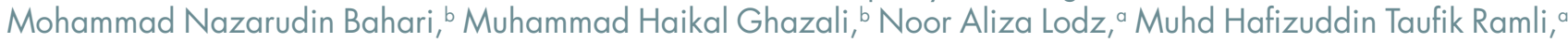
Nur Liana Ab Majid, ${ }^{a}$ Miaw Yn Jane Ling, ${ }^{a}$ Muhammad Fadhli Mohd Yusoff, ${ }^{a}$ Noor Ani Ahmad, ${ }^{a}$ Anita Suleiman, ${ }^{c}$ Ahmad Faudzi Yusoff, d Venugopalan Balan ${ }^{b}$ and Sha'ari Ngadiman ${ }^{b}$

Correspondence to Wan Shakira Rodzlan Hasani (email: shaki_iera@yahoo.com or wshakira@moh.gov.my)

Background: Pre-existing comorbidities can predict severe disease requiring intensive care unit (ICU) admission among COVID-19 cases. We compared comorbidities, clinical features and other predictive factors between COVID-19 patients requiring ICU admission for intubation/mechanical ventilation and all other COVID-19 cases in Selangor, Malaysia.

Method: Field data collected during the COVID-19 outbreak in Selangor, Malaysia, up to 13 April 2020 were used, comprising socio-demographic characteristics, comorbidities and presenting symptoms of COVID-19 cases. ICU admission was determined from medical records. Multiple logistic regression analysis was performed to identify factors associated with ICU admission requiring intubation/mechanical ventilation among COVID-19 cases.

Results: A total of 1287 COVID-19-positive cases were included for analysis. The most common comorbidities were hypertension (15.5\%) and diabetes (11.0\%). More than one third of cases presented with fever $(43.8 \%)$ or cough (37.1\%). Of the 25 cases that required intubation/mechanical ventilation, $68.0 \%$ had hypertension, $88.0 \%$ had fever, $40.0 \%$ had dyspnoea and $44.0 \%$ were lethargic. Multivariate regression showed that cases that required intubation/ mechanical ventilation had significantly higher odds of being older (aged $\geq 60$ years) [adjusted odds ratio (aOR) $=3.9$ ] and having hypertension ( $a O R=5.7)$, fever $(a O R=9.8)$, dyspnoea $(a O R=9.6)$ or lethargy $(a O R=7.9)$ than cases that did not require intubation/mechanical ventilation.

Conclusion: The COVID-19 cases in Selangor, Malaysia requiring intubation/mechanical ventilation were significantly older, with a higher proportion of hypertension and symptoms of fever, dyspnoea and lethargy. These risk factors have been reported previously for severe COVID-19 cases, and highlight the role that ageing and underlying comorbidities play in severe outcomes to respiratory disease.

$\mathrm{C}$ oronavirus disease 2019 (COVID-19) is an infectious disease caused by severe acute respiratory syndrome coronavirus 2 (SARS-CoV-2). The infection was first detected in Wuhan, China, and has since spread across mainland China ${ }^{1}$ and all over the world. COVID-19 is the third coronavirus infection that has spread widely, after SARS and Middle East respiratory syndrome (MERS). ${ }^{2}$ On 11 March 2020, WHO declared COVID-19 a pandemic. ${ }^{3}$ As of 14 April 2020, COVID-19 had led to 1848439 diagnosed cases and 117217 deaths worldwide. ${ }^{4}$ Up to 14 April 2020, Malaysia has had a total of 4987 infected people and 82 deaths. $^{5}$

With the increasing numbers of confirmed cases and fatalities due to COVID-19, underlying comorbidities such as cardiovascular diseases and immune deficiency, especially among elderly patients, have been shown to be predictors of severe disease outcomes and poor prognoses in COVID-19 patients. ${ }^{6-8}$ Severe cases of

\footnotetext{
Institute for Public Health, National Institutes of Health, Ministry of Health Malaysia, Setia Alam, Selangor, Malaysia.

Selangor State Health Department, Ministry of Health Malaysia, Shah Alam, Selangor, Malaysia.

Disease Control Division, Ministry of Health Malaysia, WP Putrajaya, Malaysia.

Institute for Medical Research, National Institutes of Health, Ministry of Health Malaysia, Setia Alam, Selangor, Malaysia.

Published: 16 February 2021

doi: 10.5365/wpsar.2020.11.3.007
} 
COVID-19 often require admission to an intensive care unit (ICU). In China, about 15\% of patients developed severe pneumonia, and about $6 \%$ required non-invasive or invasive ventilatory support. ${ }^{9}$

Early identification of the risk factors of severe COVID-19 disease requiring intensive care in hospital would be helpful for managing hospital admissions. Studies in China and Italy suggest that the risk factors for severe COVID-19 include underlying comorbidities. ${ }^{10,11}$ Therefore, we compared the comorbidities, clinical features and other predictive factors of COVID-19 patients requiring admission to ICU for intubation/mechanical ventilation with all other COVID-19 cases in Selangor, Malaysia.

\section{METHODS}

In this retrospective study, data were collected during a COVID-19 outbreak in Selangor, Malaysia, a state on the west coast of peninsular Malaysia. At the time of the study, Selangor had recorded the highest number of COVID-19 cases in the country, with the first case reported on 4 February 2020. The analysis included all laboratory-confirmed cases in the state up to 13 April 2020. Cases were confirmed by reverse transcriptase polymerase chain reaction (RT-PCR) testing. ${ }^{12}$

Descriptive methods were used to analyse sociodemographic characteristics, comorbidities, clinical presentation and the proportion of ICU admissions requiring intubation/mechanical ventilation. Clinical and sociodemographic characteristics were derived from case investigation reports obtained from district health offices in charge of each patient. The symptoms were self-reported during telephone interviews of cases by district health officers upon notification of a positive COVID-19 case. Admission to ICU for intubation/mechanical ventilation was verified from hospital records.

Multiple logistic regression analysis was performed to identify factors associated with intubation/mechanical ventilation among COVID-19 cases. The outcome variable was ICU admission requiring intubation/mechanical ventilation. The predictor variables included a history of hypertension, diabetes, heart disease, chronic respiratory disease (including asthma, chronic obstructive pulmonary disease and emphysema), cancer and kidney disease and the main symptoms of COVID-19, such as fever, cough, dyspnoea, lethargy, arthralgia, myalgia, headache and diarrhoea. Variables with $P$ values $<0.25$, based on Wald $x 2$ statistics in univariate analysis, ${ }^{13}$ as well as those variables considered to be biologically plausible, were selected for the multivariate analysis.

The final model included sex, age, hypertension, diabetes, heart disease, fever, cough, dyspnoea and lethargy. The univariate test $P$ value cut-off was set at 0.25 because the usual level of 0.05 may fail to identify variables known to be important. ${ }^{14} \mathrm{~A}$ backwards selection method was used to select variables. Starting with all candidate variables, the least significant effect for the model was removed, and the process was repeated until no further variables could be deleted without a statistically significant loss of fit. After this process, only age, hypertension, fever, dyspnoea and lethargy were significant in the multivariate model. To avoid over-fitting the model, only these five variables were included. Possible multicollinearity and all possible two-way interaction terms were checked one by one with main effect. Goodness-of-fit statistics were used to assess the fit of the regression model against actual outcomes. Two-sided $P$ values $<0.05$ were considered statistically significant. Statistical Package Social Sciences (SPSS) statistical software version 24 was used for the analysis.

The study was conducted in accordance with the Declaration of Helsinki and ethical approval was obtained from the National Medical Research Registry, Ministry of Health Malaysia (registration number NMRR-20-720 54598). The requirement for written informed consent was waived given the context of an emerging infectious disease.

\section{RESULTS}

In total, 1287 laboratory-confirmed cases of COVID-19 in Selangor were included in the analysis. Of these, 750 patients $(58.3 \%)$ were male and most $(74.0 \%)$ were of Malay ethnicity. The median age was 36 years, and the highest percentage of cases were in people aged 18-29 years. The most commonly reported comorbidities were hypertension (15.5\%) and diabetes (11.0\%). More than one third of cases presented with fever $(43.8 \%)$ or cough (37.1\%); only $5.5 \%$ experienced dyspnoea, and $6.1 \%$ were lethargic (Table 1). 
Table 1. Socio-demographic characteristics, comorbidity and clinical presentation of COVID-19positive cases in Selangor $(n=1287)$

\begin{tabular}{|c|c|}
\hline Characteristic & $\begin{array}{l}\text { COVID-19-positive } \\
\text { cases }\end{array}$ \\
\hline \multicolumn{2}{|l|}{ Sex, $n(\%)$} \\
\hline Male & $750(58.3)$ \\
\hline Female & $537(41.7)$ \\
\hline \multicolumn{2}{|l|}{ Age (years) } \\
\hline Median (IQR) & $36.0(30.0)$ \\
\hline Mean (SD) & $38.8(18.2)$ \\
\hline \multicolumn{2}{|l|}{ Age groups, $n(\%)$} \\
\hline$<18$ & $116(9.0)$ \\
\hline $18-29$ & $366(28.4)$ \\
\hline $30-39$ & $239(18.6)$ \\
\hline $40-49$ & $151(11.7)$ \\
\hline $50-59$ & $214(16.6)$ \\
\hline$\geq 60$ & $201(15.6)$ \\
\hline \multicolumn{2}{|l|}{ Ethnicity, $n$ (\%) } \\
\hline Malay & $952(74.0)$ \\
\hline Chinese & $118(9.2)$ \\
\hline Indian & $43(3.3)$ \\
\hline Other & $174(13.5)$ \\
\hline \multicolumn{2}{|l|}{ Nationality, $\boldsymbol{n}(\%)$} \\
\hline Malaysian & $1122(87.2)$ \\
\hline Non-Malaysian & $165(12.8)$ \\
\hline \multicolumn{2}{|l|}{ Comorbid conditions, $n$ (\%) } \\
\hline Hypertension & $200(15.5)$ \\
\hline Diabetes & $141(11.0)$ \\
\hline Heart disease or other problem & $50(3.9)$ \\
\hline Chronic respiratory disease & $40(3.1)$ \\
\hline Chronic kidney disease & $18(1.4)$ \\
\hline Cancer & $7(0.5)$ \\
\hline Current smoker & $57(4.4)$ \\
\hline \multicolumn{2}{|l|}{ Symptoms, $n$ (\%) } \\
\hline Fever & $564(43.8)$ \\
\hline Cough & $477(37.1)$ \\
\hline Lethargy & $78(6.1)$ \\
\hline Dyspnoea & $71(5.5)$ \\
\hline Headache & $71(5.5)$ \\
\hline Myalgia & $53(4.1)$ \\
\hline Diarrhoea & $41(3.3)$ \\
\hline Arthralgia & $31(2.4)$ \\
\hline \multicolumn{2}{|l|}{ Hospital admission ( $n=1156), n(\%)$} \\
\hline $\begin{array}{l}\text { Intubated (invasive ventilator } \\
\text { support) }\end{array}$ & $25(2.2)$ \\
\hline Not intubated & $1131(97.9)$ \\
\hline
\end{tabular}

Of the 1156 patients who were hospitalized, 25 (2.2\%) were admitted to the ICU and required intubation/ mechanical ventilation. Of these 25 cases, 14 were aged $\geq 60$ years, 17 had hypertension, 10 had diabetes, 22 presented with fever, 14 with cough, 10 with dyspnoea and 11 with lethargy (Table 2).

The final multivariate model demonstrated that the odds of COVID-19 cases that required intubation/ mechanical ventilation being older ( $\geq 60$ years) were 4.2 times (aOR: 4.24, 95\% Cl: 1.59-11.34) higher than the odds of all other cases being older, after controlling for sex, comorbidities and presenting symptoms. COVID-19 cases that required intubation/mechanical ventilation also had 6.0 times higher odds of having underlying hypertension (aOR: 5.97, 95\% Cl: 2.27-15.72) and presenting with the symptoms of fever (aOR: 7.91, 95\% Cl: 2.18-28.73), dyspnoea (aOR: $8.47,95 \% \mathrm{Cl}: 3.08-23.29$ ) or lethargy (aOR: 7.57, 95\% Cl: 2.89-19.86), compared with the odds for these risk factors in all other cases (Table 3 ). When age was used as a continuous variable in the same regression model, every 1-year increase in age increased the odds of requiring intubation/mechanical ventilation by $8 \%$ (aOR: $1.08,95 \% \mathrm{Cl}: 1.03-1.12$ ).

Univariable analyses were also conducted for cancer, chronic kidney disease, current smoker, chronic respiratory disease and symptoms at presentation such as diarrhoea, arthralgia, myalgia and headache. The results are not presented in the table because the small sample sizes did not give meaningful ORs and Cls.

\section{DISCUSSION}

In this study, the proportion of COVID-19 cases requiring intubation/mechanical ventilation in Selangor, Malaysia $(2.2 \%)$ was similar to studies in China $(2.3-3.0 \%)^{10,15}$ but lower than that in the United States of America $(20.2-22.3 \%){ }^{16,17}$ These differences may be due to differences in guidelines for intubation and mechanical ventilation as well as ICU bed capacity. We also found that underlying hypertension and diabetes were the most common comorbidities in all COVID-19 cases, consistent with the findings in Wuhan ${ }^{18}$ and in a meta-analysis of the prevalence of comorbidities in COVID-19 patients. ${ }^{19}$ Bornstein et al. ${ }^{20}$ reported that hypertension and type-II diabetes were the most common comorbidities in infected COVID-19 patients, 
Table 2. Numbers of intubated cases of COVID-19 by socio-demographic, NCD comorbidity and clinical presentation

\begin{tabular}{|c|c|c|}
\hline Variables & $\begin{array}{l}\text { Intubated (invasive mechanical ventilation) } \\
\qquad(n=25)\end{array}$ & $\begin{array}{l}\text { Not intubated } \\
\quad(n=1262)\end{array}$ \\
\hline \multicolumn{3}{|l|}{ Sex, $n(\%)$} \\
\hline Male & $18(72.9)$ & $732(58.0)$ \\
\hline Female & $7(28.0)$ & $530(42.0)$ \\
\hline \multicolumn{3}{|l|}{ Age group, $n(\%)$} \\
\hline$<60$ & $11(44.0)$ & $1075(85.2)$ \\
\hline$\geq 60$ & $14(56.0)$ & $187(14.8)$ \\
\hline \multicolumn{3}{|l|}{ Comorbid conditions, $n(\%)$} \\
\hline Hypertension & $17(68.0)$ & $183(14.5)$ \\
\hline Diabetes & $10(40.0)$ & $131(10.4)$ \\
\hline Heart disease & $4(16.0)$ & $46(3.6)$ \\
\hline Chronic respiratory disease & $0(0.0)$ & $40(3.2)$ \\
\hline Chronic kidney disease & $3(12.0)$ & $15(1.2)$ \\
\hline Cancer & $0(0.0)$ & $7(0.6)$ \\
\hline Current smoker & $1(4.0)$ & $56(4.4)$ \\
\hline \multicolumn{3}{|l|}{ Symptoms, $n(\%)$} \\
\hline Fever & $22(88.0)$ & $542(42.9)$ \\
\hline Cough & $14(56.0)$ & $463(36.7)$ \\
\hline Lethargy & $11(44.0)$ & $67(5.3)$ \\
\hline Dyspnoea & $10(40.0)$ & $61(4.8)$ \\
\hline Diarrhoea & $3(12.0)$ & $38(3.0)$ \\
\hline Arthralgia & $1(4.0)$ & $30(2.4)$ \\
\hline Myalgia & $1(4.0)$ & $52(4.1)$ \\
\hline Headache & $0(0.0)$ & $71(5.6)$ \\
\hline
\end{tabular}

due to metabolic inflammation caused by the infection, which compromises the immune system. Diabetes and hypertension were also reported as the most common comorbidities with other coronaviruses, such as SARS$\mathrm{CoV}$ and MERS-CoV. ${ }^{21}$

Older age and underlying comorbidities are predictors of severe outcomes in viral infections generally, ${ }^{22,23}$ and we found that the proportion of COVID-19 patients who required intubation/mechanical ventilation increased with age. The regression model showed that the odds of requiring intubation/mechanical ventilation was 4.2 times higher for adults aged $\geq 60$ years after controlling for comorbidities and presenting symptoms. As in other studies, the risk for a severe outcome is higher for older people. Data from China indicate that older adults with severe underlying health conditions are at higher risk for severe COVID-19-associated illness and death. ${ }^{24}$ Reports from Italy also suggested that the risk factors for severe disease include older age and the presence of at least one underlying health condition among COVID-19 cases. ${ }^{11}$
Preliminary findings from the United States of America suggested that people with underlying health conditions are at higher risk for severe disease from COVID-19. ${ }^{25}$ A study in China showed that almost 70\% of COVID-19 patients who were admitted to an ICU had comorbidities. ${ }^{26}$ Our study shows that COVID-19 patients with underlying hypertension contributed to a high percentage of ICU admissions requiring intubation/ mechanical ventilation. Cases that required intubation/ mechanical ventilation also had six times the odds of having underlying hypertension after adjustment for age, other comorbidities and clinical presentation. Hypertension was the most common comorbidity that predicted a poor prognosis in patients with COVID-19. In a systematic review and meta-analysis by Yang et al., ${ }^{26}$ the pooled odds of hypertension in patients with severe, as compared with non-severe disease, was 2.36 (95\% Cl: 1.46-3.83).

Other than age and underlying hypertension, the presenting symptoms of COVID-19 infection also predict a severe outcome. As in other studies, the most common 
Table 3. Factors associated with intubation among positive COVID-19 cases in a binary logistic regression model $(n=1287)$

\begin{tabular}{|c|c|c|c|c|c|c|}
\hline \multirow{2}{*}{ Risk factor } & \multicolumn{3}{|c|}{ Simple logistic regression } & \multicolumn{3}{|c|}{ Multiple logistic regression } \\
\hline & $\boldsymbol{b}$ & Crude OR $(95 \% \mathrm{Cl})$ & $\boldsymbol{P}$ & $\boldsymbol{b}$ & Adjusted OR* (95\% Cl) & $\boldsymbol{P}$ \\
\hline \multicolumn{7}{|l|}{ Sex } \\
\hline Male & & 1 & & & & \\
\hline Female & -0.62 & $0.54(0.22-1.30)$ & 0.166 & & & \\
\hline \multicolumn{7}{|l|}{ Age group (years) } \\
\hline$<60$ & & 1 & & & 1 & \\
\hline$\geq 60$ & 1.99 & $7.32(3.27-16.36)$ & $<0.001$ & 1.45 & $4.24(1.59-11.34)$ & 0.004 \\
\hline \multicolumn{7}{|l|}{ Hypertension } \\
\hline No & & 1 & & & 1 & \\
\hline Yes & 2.53 & $12.53(5.33-29.46)$ & $<0.001$ & 1.79 & $5.97(2.27-15.72)$ & $<0.001$ \\
\hline \multicolumn{7}{|l|}{ Diabetes } \\
\hline No & & 1 & & & 1 & \\
\hline Yes & 1.75 & $5.76(2.53-13.07)$ & $<0.001$ & & & \\
\hline \multicolumn{7}{|l|}{ Heart disease } \\
\hline No & & 1 & & & 1 & \\
\hline Yes & 1.62 & $5.04(1.66-15.26)$ & 0.004 & & & \\
\hline \multicolumn{7}{|l|}{ Fever at presentation } \\
\hline No & & 1 & & & 1 & \\
\hline Yes & 2.28 & $9.74(2.90-32.72)$ & $<0.001$ & 2.07 & $7.91(2.18-28.73)$ & 0.002 \\
\hline \multicolumn{7}{|l|}{ Cough at presentation } \\
\hline No & & 1 & & & 1 & - \\
\hline Yes & 0.787 & $2.20(0.99-4.88)$ & 0.053 & & & \\
\hline \multicolumn{7}{|l|}{ Dyspnoea at presentation } \\
\hline No & & 1 & & & 1 & \\
\hline Yes & 2.58 & $13.13(5.66-30.42)$ & $<0.001$ & 2.14 & 8.47 (3.08-23.29) & $<0.001$ \\
\hline \multicolumn{7}{|l|}{ Lethargy at presentation } \\
\hline No & & 1 & & & 1 & \\
\hline Yes & 2.64 & $14.01(6.13-32.05)$ & $<0.001$ & 2.03 & $7.57(2.89-19.86)$ & $<0.001$ \\
\hline
\end{tabular}

* Backwards multiple logistic regression was applied. Multicollinearity and interactions were checked and not found. Hosmer Lameshow test $P=0.808$, classification table (overall correctly classified percentage $=98.0 \%$ ) and area under ROC curve $=94.3 \%$ were used to check model fitness.

Univariable analyses were also conducted for cancer, chronic kidney disease, current smoker, chronic respiratory disease and symptoms at presentation such as diarrhoea, arthralgia, myalgia and headache. The results are not presented in the table because small cell sizes did not give meaningful ORs and Cls.

presenting symptoms in this study were fever, cough, dyspnoea and lethargy. ${ }^{10,15,18,28,29}$ Our findings indicate that symptomatic COVID-19 patients with fever, dyspnoea and lethargy have a strong, significant risk for intubation/ mechanical ventilation. Li et al. $^{30}$ demonstrated significant differences in clinical symptoms and computed tomography scan manifestation between patients with or without severe or critical COVID-19 after control for age and comorbidities. This finding is important for clinicians in stratifying risk for their patients according to presenting symptoms. Although dyspnoea is a known risk factor for intubation/mechanical ventilation, patients presenting with fever or lethargy should also be closely monitored.

Our study has some notable limitations. First, the number of cases requiring intubation/mechanical ventilation was small at 25 cases (2.2\%). Furthermore, the data were derived from a report from a single state in Malaysia and may not represent the national population. Data on ICU admissions, comorbidities and outcomes were missing for $<20 \%$ of patients. Despite these limitations, our results are consistent with previous studies of COVID-19 cases.

\section{CONCLUSION}

COVID-19 cases that were intubated and ventilated had higher odds of being aged $\geq 60$ years, having hypertension and presenting with fever, dyspnoea or lethargy compared with all other COVID-19 cases. Older people and those with comorbidities such as hypertension should be prioritised for hospital care as they are more vulnerable to severe disease and progression when infected with SARS-CoV-2. 


\section{Acknowledgements}

We thank the Director-General of Health Malaysia for his permission to publish this article. We also thank the Selangor State Health Office and all the district health offices in Selangor for their cooperation and support for this study.

\section{Conflict of interest}

None declared.

Funding

\section{Ministry of Health Malaysia}

\section{References}

1. Li Q, Guan X, Wu P, Wang X, Zhou L, Tong $Y$, et al. Early transmission dynamics in Wuhan, China, of novel coronavirus-infected pneumonia. N Engl J Med. 2020;382(13):1199-207.

2. Morens DM, Taubenberger JK. Influenza cataclysm, 1918. N Engl J Med. 2018;379(24):2285-7.

3. WHO announces COVID-19 outbreak a pandemic - WHO Director-General's opening remarks at the media briefing on COVID-19 - 11 March 2020. Geneva: Wold Health Organization; 2020. Available from: https://www.who.int/director-general/ speeches/detail/who-director-general-s-opening-remarks-at-themedia-briefing-on-covid-19--11-march-2020, accessed 14 April 2020.

4. Coronavirus disease (COVID-19) pandemic: Coronavirus disease (COVID-19) outbreak situation. Geneva: World Health Organization; 2020. Available from: https://www.who.int/emergencies/diseases/novel-coronavirus-2019, accessed 14 April 2020.

5. Latest COVID-19 statistic in Malaysia by $\mathrm{MOH}$ as at $5: 00 \mathrm{pm}$, April 14th. Kuala Lumpur: Ministry of Health Malaysia; 2020. Available from: https://www.moh.gov.my/index.php/pages/ view/2019-ncov-wuhan, accessed 14 April 2020.

6. Li B, Yang J, Zhao F, Zhi L, Wang X, Liu L, et al. Prevalence and impact of cardiovascular metabolic diseases on COVID-19 in China. Clin Res Cardiol. 2020;109(5):531-8.

7. Ruan Q, Yang K, Wang W, Jiang L, Song J. Clinical predictors of mortality due to COVID-19 based on an analysis of data of 150 patients from Wuhan, China. Intensive Care Med. 2020;46(5):13.

8. Zhou F, Yu T, Du R, Fan G, Liu Y, Liu Z, et al. Clinical course and risk factors for mortality of adult inpatients with COVID-19 in Wuhan, China: a retrospective cohort study. Lancet. 2020;395(10229):1054-62.

9. Xie J, Tong Z, Guan X, Du B, Qiu H, Slutsky AS. Critical care crisis and some recommendations during the COVID-19 epidemic in China. Intensive Care Med. 2020;46(5):837-40.
10. Guan WJ, Ni ZY, Hu Y, Liang WH, Ou CQ, He JX, et al. Clinical characteristics of coronavirus disease 2019 in China. N Engl J Med. 2020;382(18):1708-20.

11. COVID-19 Surveillance Group. Characteristics of COVID-19 patients dying in Italy: report based on available data on March 20th, 2020. Rome: Instituto Superiore di Sanita; 2020.

12. Laboratory testing for coronavirus disease (COVID-19) in suspected human cases: interim guidance, 19 March 2020. Geneva: World Health Organization; 2020 (https://apps.who.int/ iris/handle/10665/331501).

13. Hosmer DW Jr, Lemeshow S, Sturdivant RX. Applied logistic regression. John Wiley \& Sons; 2013. doi:10.1002/9781118548387

14 Mickey RM, Greenland S. The impact of confounder selection criteria on effect estimation. Am J Epidemiol. 1989;129(1):12537.

15. Yang W, Cao Q, Qin L, Wang X, Cheng Z, Pan A, et al. Clinical characteristics and imaging manifestations of the 2019 novel coronavirus disease (COVID-19): A multi-center study in Wenzhou city, Zhejiang, China. J Infect. 2020;80(4):388-93.

16. Richardson S, Hirsch JS, Narasimhan M, Crawford JM, McGinn T, Davidson KW, et al. Presenting characteristics, comorbidities, and outcomes among 5700 patients hospitalized with COVID-19 in the New York City area. JAMA. 2020;323(20):2052-9.

17. Petrilli CM, Jones SA, Yang J, Rajagopalan H, O'Donnell LF, Chernyak $Y$, et al. Factors associated with hospitalization and critical illness among 4,103 patients with COVID-19 disease in New York City. MedRxiv. 2020. Available from: https://www. medrxiv.org/content/10.1101/2020.04.08.20057794v1.

18. Huang C, Wang Y, Li X, Ren L, Zhao J, Hu Y, et al. Clinical features of patients infected with 2019 novel coronavirus in Wuhan, China. Lancet. 2020;395(10223):497-506.

19. Baradaran A, Ebrahimzadeh MH, Baradaran A, Kachooei AR. Prevalence of comorbidities in COVID-19 patients: a systematic review and meta-analysis. Arch Bone Jt Surg. 2020;8(Suppl 1):247-55

20. Bornstein SR, Dalan R, Hopkins D, Mingrone G, Boehm BO. Endocrine and metabolic link to coronavirus infection. Nat Rev Endocrinol. 2020;16(6):297-8.

21. Yang JK, Feng Y, Yuan MY, Yuan SY, Fu HJ, Wu BY, et al. Plasma glucose levels and diabetes are independent predictors for mortality and morbidity in patients with SARS. Diabet Med. 2006;23(6):623-8.

22. McMichael TM, Currie DW, Clark S, Pogosjans S, Kay M, Schwartz NG, et al. Epidemiology of covid-19 in a long-term care facility in King County, Washington. N Engl J Med. 2020;382(21):200511.

23. Koff WC, Williams MA. Covid-19 and immunity in aging populations - a new research agenda. N Engl J Med. 2020;383(9):8045.

24. Epidemiology Working Group for NCIP Epidemic Response, Chinese Centre for Disease Control and Prevention. The epidemiological characteristics of an outbreak of 2019 novel coronavirus diseases (COVID-19) in China. Zhonghua Liu Xing Bing Xue Za Zhi. 2020;41(2):145-51. 
25. Chow N, Fleming-Dutra K, Gierke R, Hall A, Hughes M, et al. Preliminary estimates of the prevalence of selected underlying health conditions among patients with coronavirus disease 2019 - United States, February 12-March 28, 2020. Morbid Mortal Wkly Rep. 2020;69(13):382.

26. Wang D, Hu B, Hu C, Zhu F, Liu X, Zhang J, et al. Clinical characteristics of 138 hospitalized patients with 2019 novel coronavirus-infected pneumonia in Wuhan, China. JAMA. 2020;323(11):1061-9.

27. Yang J, Zheng Y, Gou X, Pu K, Chen Z, Guo Q, et al. Prevalence of comorbidities in the novel Wuhan coronavirus (COVID-19) infection: a systematic review and meta-analysis. Int J Infect Dis. 2020;94:91-5.
28. Chen J, Qi T, Liu L, Ling Y, Qian Z, Li T, et al. Clinical progression of patients with COVID-19 in Shanghai, China. J Infect. 2020;80(5):e1-6.

29. Huang R, Zhu L, Xue L, Liu L, Yan X, Wang J, et al. Clinical findings of patients with coronavirus disease 2019 in Jiangsu province, China: A retrospective, multi-center study. PLoS Negl Trop Dis. 2020;14(5):e0008280.

30. Li K, Wu J, Wu F, Guo D, Chen L, Fang Z, et al. The clinical and chest $\mathrm{CT}$ features associated with severe and critical COVID-19 pneumonia. Invest Radiol. 2020;55(6):327-31. 